\title{
Implementation of the Manufacturing Skills in a Freshman-Level CAD/CAM Course
}

Dr. Sung-Hwan Joo, Grand Valley State University

Dr. Joo is an associate professor at School of Engineering, Grand Valley State University, MI, USA. $\mathrm{He}$ is a member of American Society of Mechanical Engineers and American Society of Engineering Education. He received Ph.D degree from the University of Oklahoma in 2006. His research areas are CAD/CAM, FEA and Design Optimization. 


\title{
Implementation of the Manufacturing Skills in a Freshman Level CAD/CAM Course
}

\begin{abstract}
The projects and assignments in freshman level CAD/CAM courses provide students a valuable chance to develop their skills further. In the past, most of assignments and projects were about designing simple mechanical (and/or electrical) system and theories without requiring any manufacturing skills. However, students need to have basic manufacturing skills as they move up to the upper level classes or when they graduate. Students who have a good manufacturing skills tend to have better hands-on skills and to be more successful as students as well as engineers.

In this specific example class, students are required to learn manufacturing skills through several unique manufacturing assignments. Three manufacturing assignments including Keychain CNC Milling, Manual G-coding and 3D printing assignments will be discussed. Students are asked to cut a plastic keychain with their own design using CAD/CAM software and CNC milling as a first assignment. As a second assignment, they are asked to design and cut the various shapes of slots in a piece of plastic without any CAD/CAM software (Manual G-coding). As a third assignment, students design and fabricate aluminum gusset. As a fourth assignment, Students bring their own 3D CAD model to 3D printer and fabricate their final semester project parts.

Students are given maximum 4 weeks for each assignment and present their final products to an instructor. In this paper, following topics will be explained and discussed. 1) History of the class projects, 2) Manufacturing assignments, 3) Course topics and schedule, 4) Semester Projects, 5) Feedback from students and 6) Conclusion and Future development of course.
\end{abstract}

\section{Introduction}

Recently, many engineering classes requires the final semester project as essential elements of the class. One of the freshman class in the Grand Valley State University; EGR-106 and 107 (Introduction to Engineering Design) has been a hands-on CAD/CAM course and used lots of different robots competitions as a final semester project. Those robots competition have been widely successful. However, some robots competitions have been challenge to some of students because of students' lack of knowledge about electronics components and manufacturing skills. So, author was looking for the new final semester project to improve students CAD/CAM and manufacturing skills rather than electronic skills.

\section{Structure of Course Sequence}

All engineering majors are currently required to take two engineering courses in first and second semesters: EGR 106 (Introduction to Engineering Design I), and EGR 107 (Introduction to Engineering Design II). These courses are typically taken in the fall and winter semester of the freshman year, respectively. The other courses that complete a typical freshman year for engineering majors are in the disciplines of Mathematics, Chemistry, Physics, Writing, and 
Statistics. As the only two discipline-specific courses in the freshman year, EGR 106 and EGR 107 have become the de facto "introduction to engineering sequence" for freshmen.

While these courses include important topical coverage, we will discuss about several manufacturing topics and projects. Manufacturing topics are being covered in the first course (EGR-106).

\subsection{Course Sequence}

In addition to manufacturing topics, this first course covers the principles and practice of multidisciplinary engineering analysis, design, construction, evaluation, and optimization. Topics include graphical communication, solid modeling, computer-aided manufacturing, structured computer programming and principles of digital and analog electronics. Professional skills such as teamwork, problem solving and communication (oral and written) are emphasized.

\subsubsection{Topics of the Course} $2^{3}$.

The duration of the course is 13 weeks. Topics of the course are shown in table 1 and table

Table 1. Topics of the Class (Lecture)

\begin{tabular}{|l|c|}
\hline \multicolumn{1}{|c|}{ TOPIC } & Duration (Week) \\
\hline $\begin{array}{l}\text { The Design Process / } \\
\text { Problem Identification }\end{array}$ & 1 \\
\hline $\begin{array}{l}\text { Preliminary Ideas / } \\
\text { Design Analysis }\end{array}$ & 1 \\
\hline Geometric Construction & 2 \\
\hline Orthographic Projection & 2 \\
\hline Primary Auxiliary Views & 1 \\
\hline Section View & 1 \\
\hline Dimensioning & 2 \\
\hline Tolerancing & 1 \\
\hline
\end{tabular}

Table 2. Topics of the Class (Manufacturing Activity)

\begin{tabular}{|l|c|}
\hline \multicolumn{1}{|c|}{ TOPIC } & Duration (Week) \\
\hline Keychain Manufacturing & 2 \\
\hline Manual G-Coding & 1 \\
\hline $\begin{array}{l}\text { Aluminum Gusset Redesign } \\
\text { Project }\end{array}$ & 3 \\
\hline Robot Design Project & 7 \\
\hline
\end{tabular}


Topics are systemically prepared and arranged to make students ready for the final robot competition project. Students are going to use the skills they learned from the class every week.

\section{Methodology of Manufacturing Skills}

Several assignments are used to teach students manufacturing skills in addition to final semester projects. Final semester projects are very important elements in the class because the projects will provide change for students to use and improve their manufacturing skills.

\subsection{Keychain Manufacturing (Individual Assignment)}

This is the first project for student. In two week, students learn how to create 3D model using CAD software ${ }^{4}$, generate G-Code and manufacture a simple keychain using a piece of plastic.

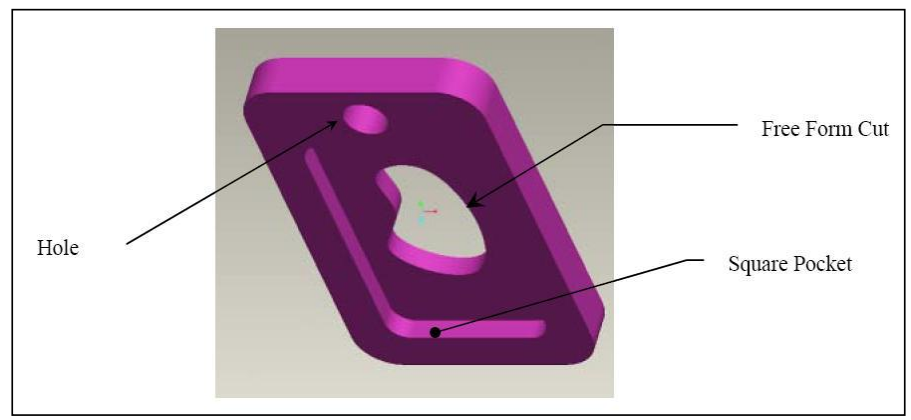

Figure 1. 3D CAD Model of Key Chain

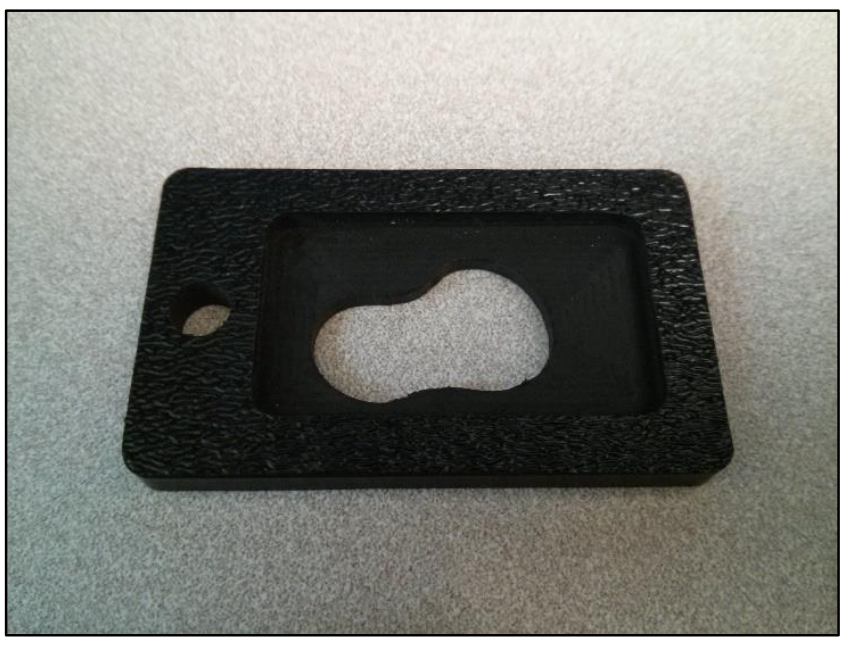

Figure 2. Example of Finished Key Chain

Detailed tutorials are provided with one hour workshop for CNC milling machine in the machine shop. This assignment has two components: CAD and CAM. Students will learn how to use $\mathrm{CNC}$ milling machine by doing this assignment. CNC milling has been a very important part of undergraduate students' essential skills. 


\subsection{Manual G-Coding (Individual Assignment)}

This is the second assignment. In the Keychain assignment, students used CAD and CAM software to generate their G-codes for CNC milling machines. However, students learn how to create simple plastic model without using CAM software in this assignment. The G-code must be manually created and the final manufactured part is compared with the 3D CAD model to verify the accuracy. This activity help students understand the basic G-code by create their own codes.

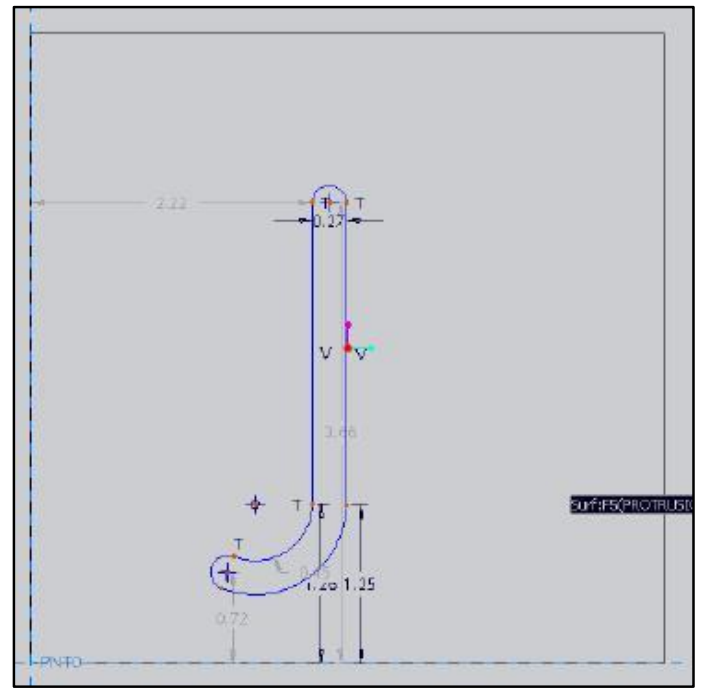

Figure 3. Manual G-coding Example

\subsection{Aluminum Gusset Redesign Project (Team Project)}

This is the first team project for student. During four weeks, students learn how to redesign, evaluate the original part using CAD software, FEA software and test the redesigned part using a material testing machine. They also learn how to work with other team members. Students are given the original aluminum gusset design and asked to improve the design using FEA software. To improve their manufacturing skills, they are asked to manufacture their redesigned gusset suing $\mathrm{CAD}$ and $\mathrm{CNC}$ milling machine. In the assignment, students learn how to design and machine a metal piece instead of plastics. 


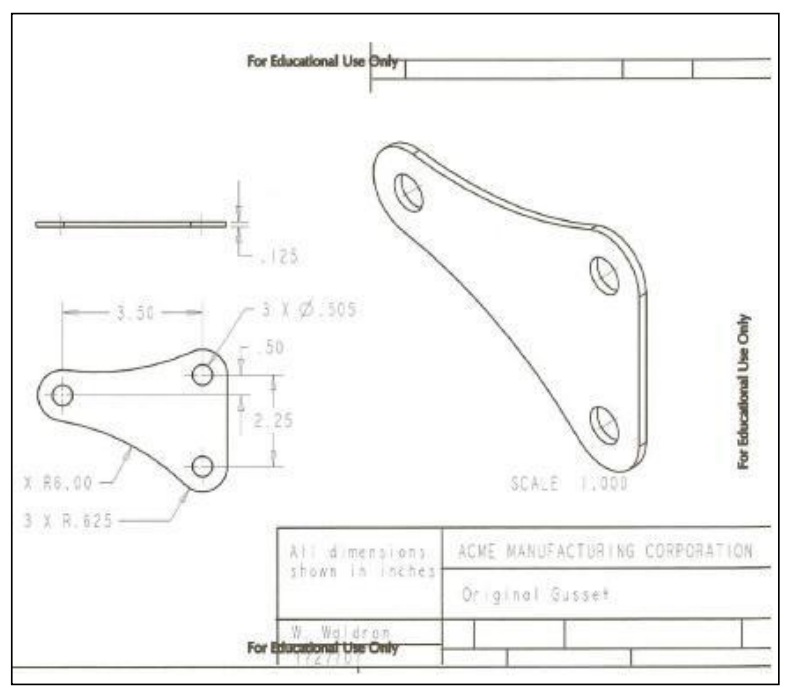

Figure 4. Original Aluminum Gusset Part

\subsection{D Printing Project (Individual Project)}

3D Printing technology has been widely popular due to the flexibility and lowered manufacturing cost. This manufacturing skill has been implemented in the course for the first time in 2016 semester. This assignment will be to fabricate at least one of the component from robot for the semester project.

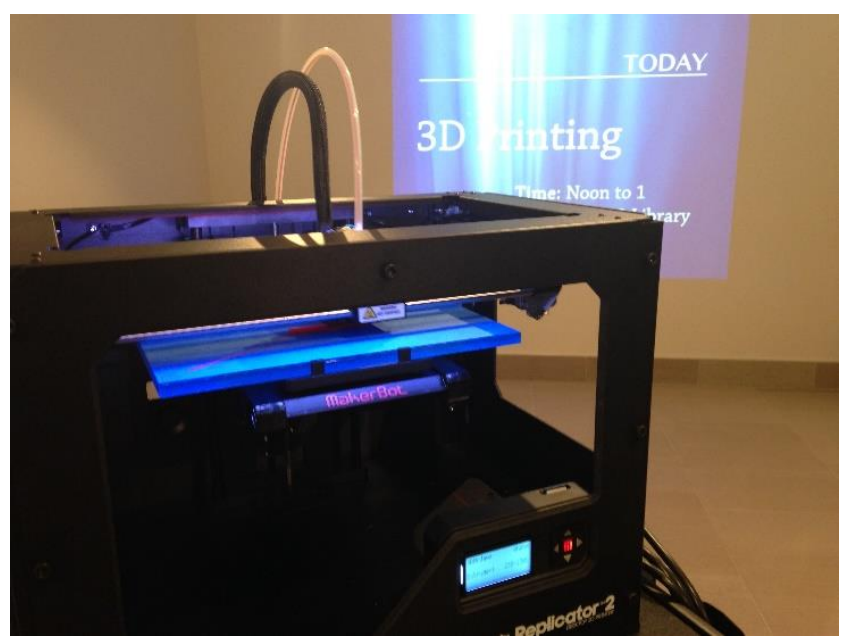

Figure 5. 3D Printing 


\subsection{Final Design Project}

This is the design team project for student. Students learn how to design, evaluate, and manufacture complete new robot for competition using CAD software through the design process. This projects improve student's various manufacturing skills. Topics of design project has been presented in table 3 .

Table 3. Topics of the Class (Final Project)

\begin{tabular}{|l|l|}
\hline Week & Robot Design Project Activities \\
\hline 7 & $\begin{array}{l}\text { Conceptual Design for Project } \\
\text { Assignment (Hand sketching) }\end{array}$ \\
\hline 8 & $\begin{array}{l}\text { Drawings for Project } \\
\text { Assignment (2D Detailed Drawings) }\end{array}$ \\
\hline 9 & $\begin{array}{l}\text { Prototyping for Project } \\
\text { Assignment (Completed Prototype) }\end{array}$ \\
\hline 10 & $\begin{array}{l}\text { CAD parts \& assembly for Project } \\
\text { Assignment (CAD parts \& assembly) }\end{array}$ \\
\hline 11 & $\begin{array}{l}\text { CAD 2D drawings of parts \& assembly for Project Assignment (Pro/E based } \\
\text { parts \& assembly Drawings) }\end{array}$ \\
\hline 12 & $\begin{array}{l}\text { Machining actual parts for Project } \\
\text { Assignment (Actual Parts for Project) }\end{array}$ \\
\hline 13 & $\begin{array}{l}\text { Physical Assembly } \\
\text { Assignment (Completed Project) }\end{array}$ \\
\hline 14 & Testing \\
\hline 15 & Competition \\
\hline
\end{tabular}

\section{Final Semester Projects using Manufacturing Skills}

Several real examples of semester projects have been presented.

\subsection{Types of Projects}

Several types of final projects have been implemented in the past 2 years. Some of the projects were completely developed. These projects were developed to improve student's manufacturing skills and teamwork.

Since the students are not ready for designing the complex electric system, the robot must be simple enough for students to build using manufacturing skills and minimum programming skills which they learned from the class.

\subsection{Catching the Falling Balls Competition}

Student design wireless autonomous controlled pre-programmed robot. 
Task is to design and build a robot that will catches the falling balls and bring them to a designated spot. For this project, students use CAD and CAM skills. At least one of main components must be built using CNC milling machine. Difficulty of manufacturing: Level 2 (1: Easiest, 5: Hardest)

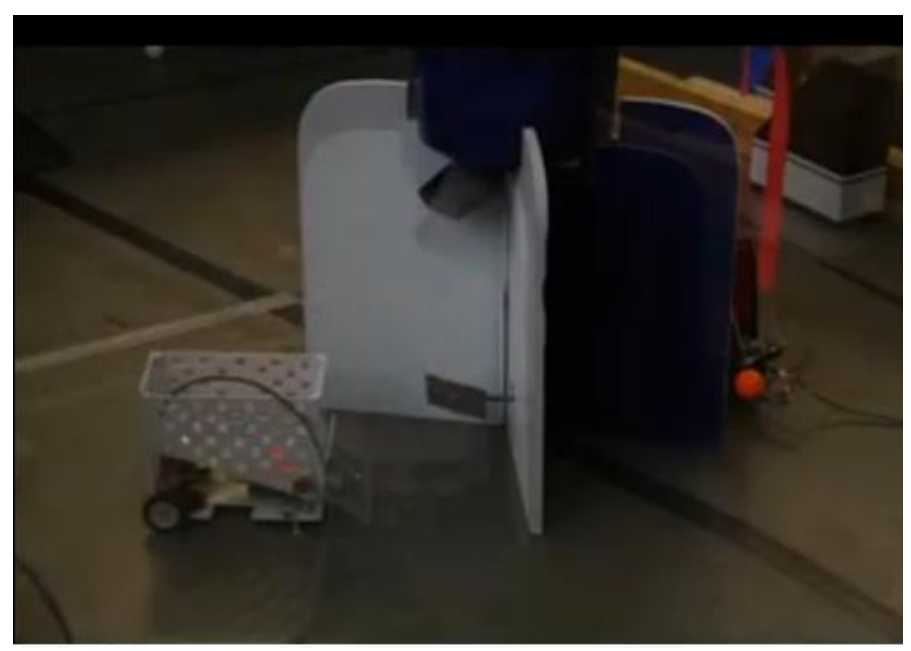

Figure 1. Catching the Falling Balls Competitions

\subsection{Robot Air Hockey Competition}

Students are asked to build a robot that plays air hockey. This competition is relatively easy for student since the robot moves only sideways. This competition will be very good for the case when you design the final project which requires manufacturing skills for the first time. Difficulty of manufacturing: Level 2. (1: Easiest, 5: Hardest)

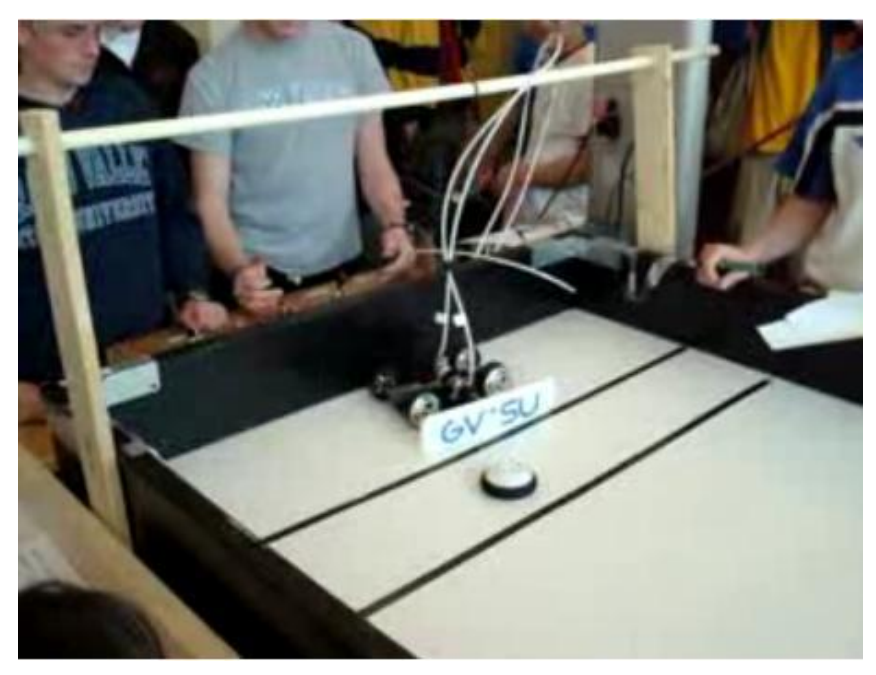

Figure 2. Robot Hockey Competitions

\subsection{Mars Rover Competition}


This competition is modified version of annual ASME SPDC Conference. Using the existing robot competition saves time and effort than developing a whole new competition ${ }^{1}$.

Task is to design and build a robot that will retrieve rocks and bring them to a designated spot. The robot must then return to its starting location, ready for another run. It must be able to surmount small obstacles, simulated by lengths of wooden " $2 \times 4$ " studding (actual dimensions 1.5 " $\times 3.5$ " or $380 \mathrm{~mm} \times 890 \mathrm{~mm}$ ), both in getting to the rocks and in bringing the rocks back to the designated deposit area.

This project requires substantial manufacturing skills. Difficulty of manufacturing: Level 4. (1: Easiest, 5: Hardest)

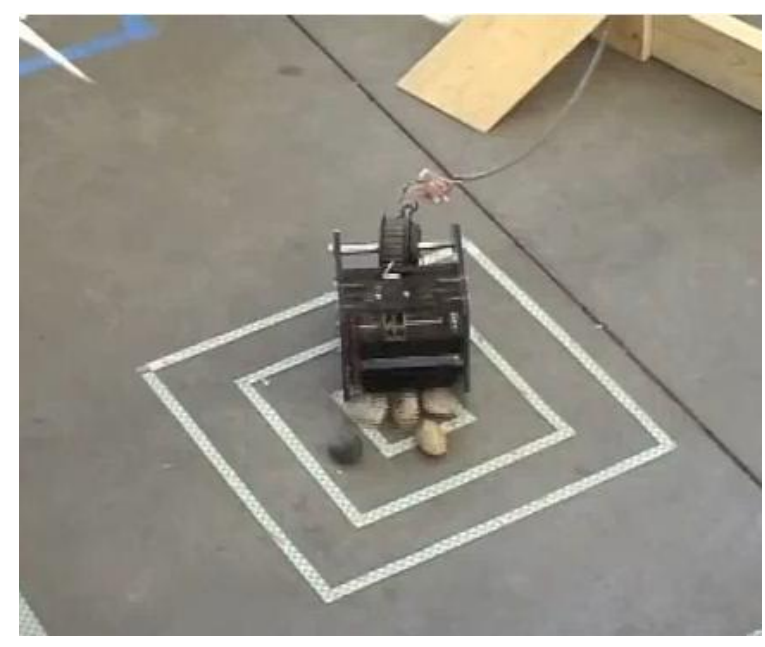

Figure 3. Robot in Mars Rover Competition

\subsection{Robot Worldcup Competition}

This competition is modified version of annual RoboCup World Championship and Conference ${ }^{2}$. Task is to design and build a robot that plays the soccer. Students competes each other with their robots. 


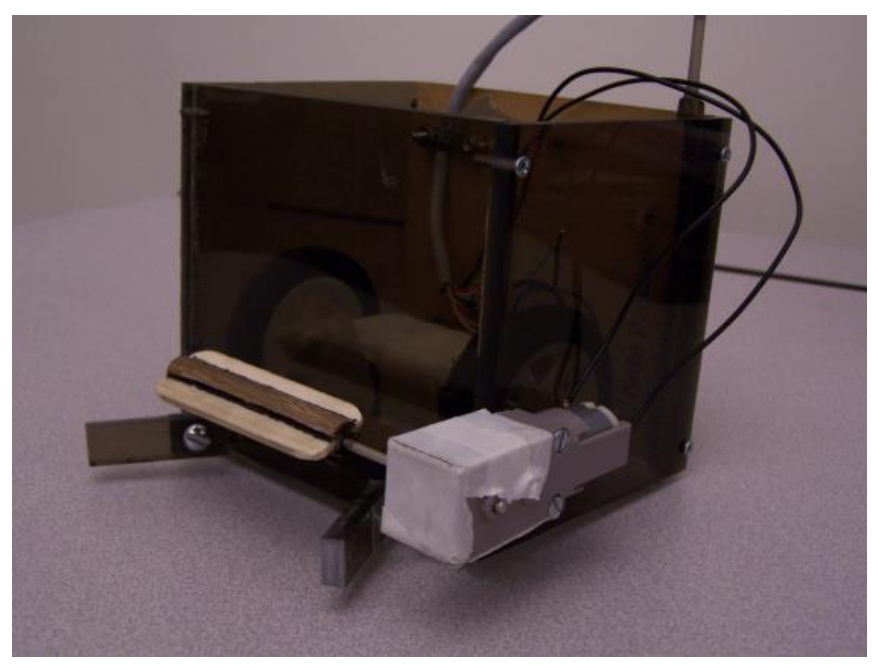

Figure 4. Robot Worldcup Competition

This project requires mid-level manufacturing skills. Difficulty of manufacturing: Level 3. (1: Easiest, 5: Hardest)

\subsection{Lane-Follower Robots}

The project is to design the robot which follows 1 inch width lines. Robots will begin at one end of a one foot wide lane. The lane will not be straight, and the sides will have rounded curves. When started, the robot must reach a finish line at least 8 feet away. Robots (e.g. wheels) must not touch the track until the race is started. This project requires mid-level manufacturing skills. Difficulty of manufacturing: Level 3. (1: Easiest, 5: Hardest)

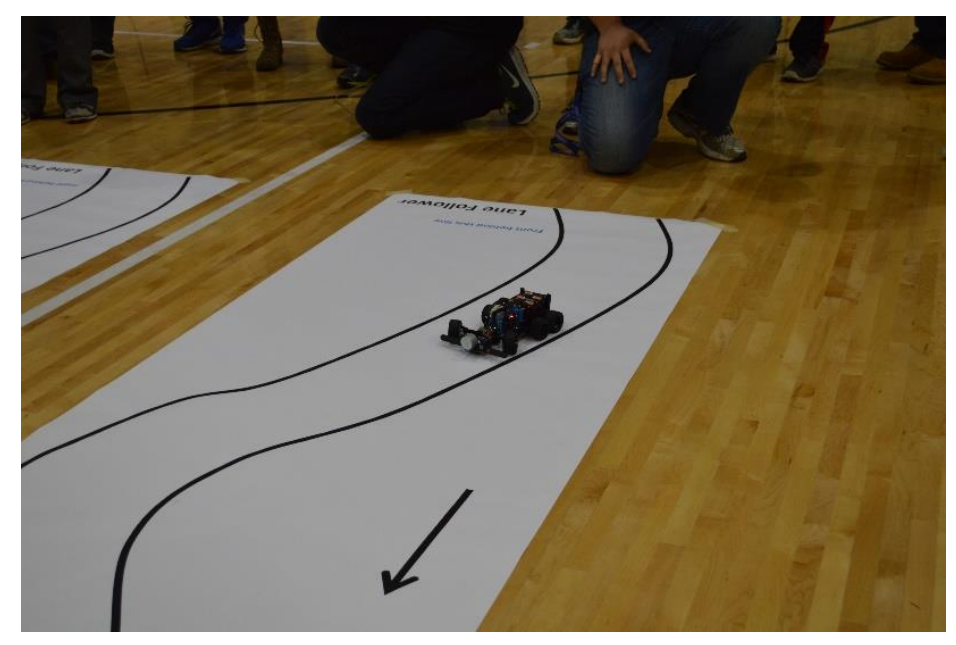

Figure 5. Lane Follower 


\subsection{Tug of War}

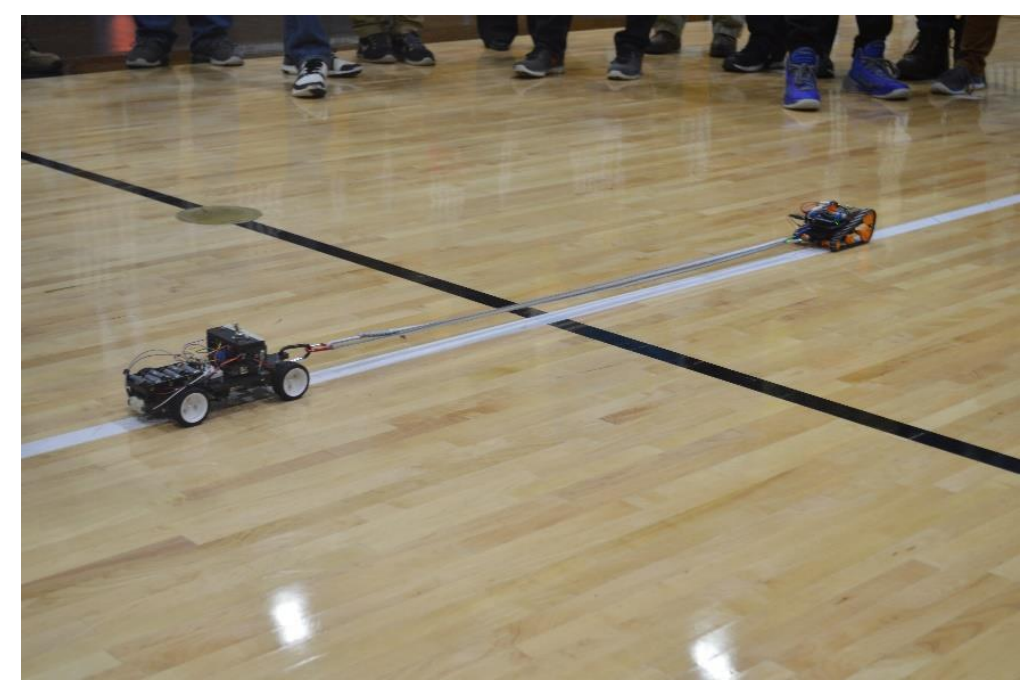

Figure 6. Tug of War

Robots are placed equal distances from a line, typically 2 feet. Once begun they try to drag their opponent. The winner will pull the other robot over the center line. This event requires an accessible $3 / 8$ " hole to attach the rope with a carabiner. This project requires low-level manufacturing skills. Difficulty of manufacturing: Level 2. (1: Easiest, 5: Hardest)

\subsection{Rhythmic Gymnastics}

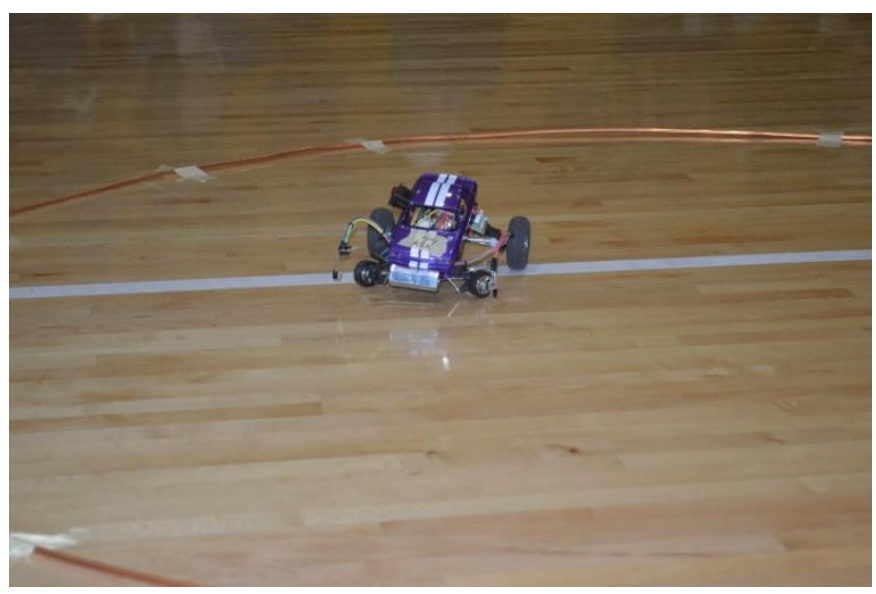

Figure 7. Rhythmic Gymnastics

Robots are to demonstrate a 20 to 60 second routine in which they will demonstrate at least 8 unique maneuvers. The robot will perform in a $3 \mathrm{ft}$ radius and return to the location that it began. Leaving the performance area will result in disqualification. Teams will provide the judges with 
a written routine before the start of competition. Teams are encouraged to provide their own music. Examples of maneuvers include, but are definitely not limited to, 360 degree spins, short turns, and figure eights. This project requires high-level manufacturing skills. Difficulty of manufacturing: Level 4. (1: Easiest, 5: Hardest)

\subsection{Line Follower}

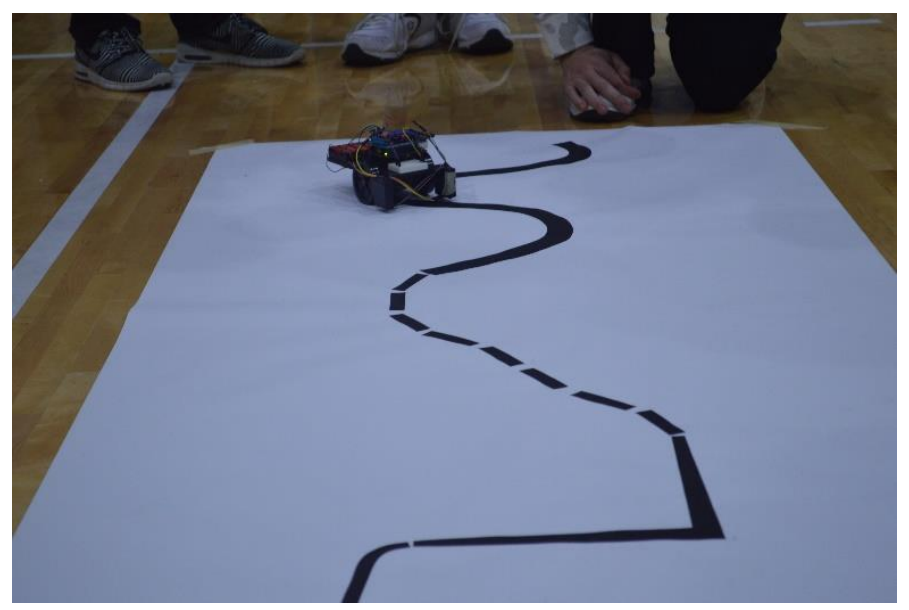

Figure 8. Line Follower

Robots are required to follow the 1 inch wide line. The course includes virtual obstacles with sharp corners, line breaks, color intensity changes, and varied width of line. The robot will begin at one end of a line then detect the lane to follow. The line has gaps in between some of the segments, a sharp corner, varying color intensity/color, and changing width of the line from $1 / 4$ " to 3 ". The complexity of the line increases from the starting point to the end for the mentioned variables.

This project requires high-level manufacturing skills. Difficulty of manufacturing: Level 4. (1: Easiest, 5: Hardest)

\subsection{Hill Climb}

The robot starts at the bottom of a hill. The hill is constructed of plywood or a similar material bent in a rounded upward slope that starts horizontal and ends vertical. The radius will be approximately 3 feet. A line is provided for guidance from the bottom to the top of the hill. The highest point reached by a wheel/roller, and held, on the slope, for at least one second, will determine the winner. 


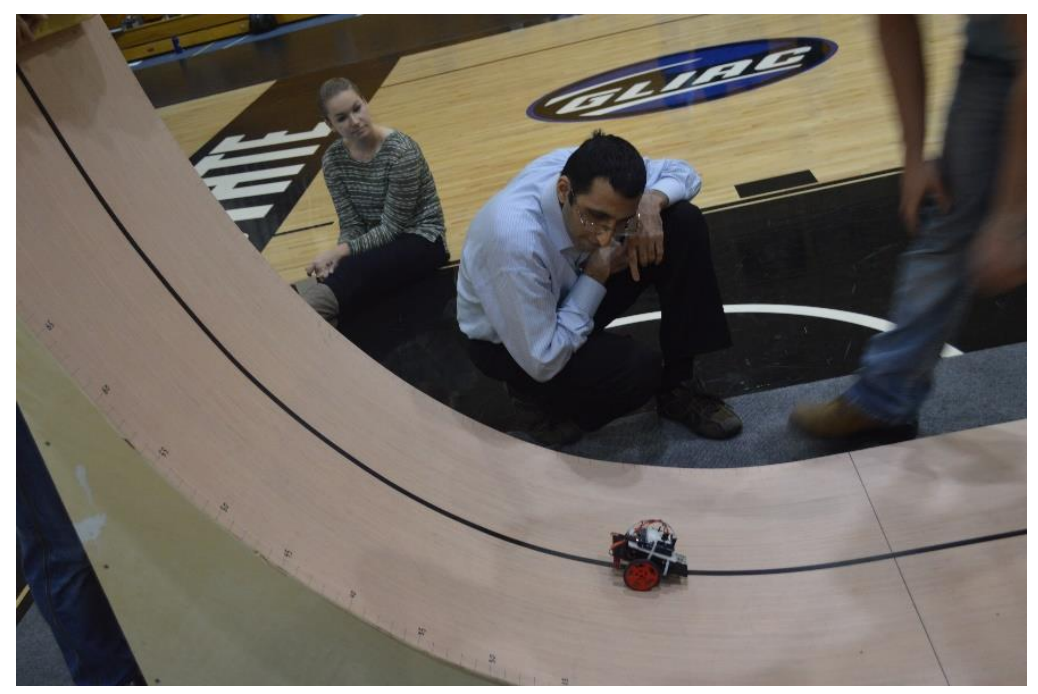

Figure 9. Hill Climb

This project requires low-level manufacturing skills. Difficulty of manufacturing: Level 1. (1: Easiest, 5: Hardest)

\section{Assessment and Survey}

\subsection{Course Outcomes Assessment}

Two ABET outcomes are assessed. One of the goal was not meet. However, the course design can be considered successful considering this courses is a freshman course.

1) Outcome Assessed: Students can design a system, component, or process to meet desired needs within realistic constraints such as economic, environmental, social, political, ethical, health and safety, manufacturability, and sustainability

Number of Samples: 35

Average Score: 3.2 (Scale 1-4)

Target: Average of 3.0

2) Outcome Assessed: Students can use the techniques, skills, and modern engineering tools necessary for engineering practice.

Number of Samples: 35

Average Score: 2.8 (Scale 1-4)

Target: Average of 3.0 


\subsection{Survey Results}

Students were asked to answer survey questions. In the end of-semester survey, students were asked three questions about their knowledge of manufacturing skills, interest in continue pursuing the engineering degree, and their self-efficacy with respect to the material (Table 4). (Group size: 70)

Table 4. Questions on End of Semester Surveys

\begin{tabular}{|c|l|}
\hline $\begin{array}{c}\text { Question } \\
\text { Number }\end{array}$ & Question \\
\hline 1 & I learned necessary basic manufacturing skills from this course \\
\hline 2 & I am more interested in the engineering after learning manufacturing skills \\
\hline 3 & $\begin{array}{l}\text { Manufacturing topics and Semester projects helped me to understand the } \\
\text { fundamental knowledge of engineering }\end{array}$ \\
\hline
\end{tabular}

Senior students was asked to answer survey questions. Students were asked three questions about manufacturing skills from their first engineering course. (Group size: 35)

Table 5. Questions on Senior Student Surveys

\begin{tabular}{|c|l|}
\hline $\begin{array}{c}\text { Question } \\
\text { Number }\end{array}$ & Question \\
\hline 1 & $\begin{array}{l}\text { I learned necessary basic manufacturing skills from this course for upper-level } \\
\text { course }\end{array}$ \\
\hline 2 & Manufacturing topics helped me to choose my major. \\
\hline 3 & More manufacturing skills must be implemented in the course in the future \\
\hline
\end{tabular}

- $83 \%$ of the freshman students agreed that they learned necessary basic manufacturing skills from this course.

- $71 \%$ of the freshman students agreed that they are more interested in the engineering after learning manufacturing skills.

- $81 \%$ of the freshman students agreed that Manufacturing topics and Semester projects helped me to understand the fundamental knowledge of engineering.

- $89 \%$ of the senior students agreed that they learned necessary basic manufacturing skills from this course for upper-level course.

- $67 \%$ of the senior students agreed that Manufacturing topics helped me to choose my majors.

- $79 \%$ of the senior students agreed that more manufacturing topics must be implemented in the course in the future. 


\section{Discussion}

Introduction of manufacturing skills to freshman is to give students the opportunity to learn one of most important elements of engineering and retain the students beyond the freshman year by applying the skills for the semester projects.

A several assignment and activities was developed to give students the opportunity to apply the manufacturing skills learned in a freshman course. Using three assignments including keychain, manual G-coding and aluminum gusset design, students learn the basic manufacturing skills. Students polishes and improve their skills while working on the semester projects.

Reviewing the student responses to the end of semester and senior student surveys reveal a number of favorable points for the manufacturing assignments and projects. The student responses demonstrated the manufacturing assignment activity was more effective in teaching the fundamental elements of engineering than the traditional lecture and theory based course. For example, the large proportion of students who expressed confidence in their ability to manufacture the required machine elements as a result of the manufacturing activity they completed. Also, more senior students who graduate expressed that the early exposure to manufacturing skills help them to prepare the upper-level course.

The more advanced manufacturing skills are needed to be introduced for the course in the future. 3D printing and laser-cutting skills can be implemented in the course because those skills are becoming a widely used manufacturing skills and easy to learn.

\section{Conclusions}

The introduction of manufacturing skills to the freshman course was a success. Students were able to use manufacturing skills to design and machine the key parts for their projects through several assignments and semester projects. Students completing this course were more confident in their ability to manufacture the components they needed in the future course and more interested in general engineering principles and concepts. 


\section{REFERENCES}

[1] Froyd JE. Integrated engineering curricula. Journal of engineering education (Washington, D.C.). 2005;94(1):147.

[2] Al-Holou N, Bilgutay NM, Corleto C, Demel JT, Felder R, Frair K, et al. In: First-year integrated curricula across engineering education coalitions. Fie; IEEE; 1998. p. 177-97.

[3] Briller V, Hanesian D, Perna AJ. In: An assessment study on replacing the engineering graphics course with the conference and exposition; June 24-27, 2001; Albuquerque, New Mexico. ASEE; 2001.

[4] Olds BM. The effect of a first-year integrated engineering curriculum on graduation rates and student satisfaction: A fundamentals of engineering design course. Proceedings of the 2001 American society of engineering education annual longitudinal study. Journal of engineering education (Washington, D.C.). 2004;93(1):23.

[5] Knight DW, Carlson LE, Sullivan J. In: Improving engineering student retention through hands-on, team based, first-year design projects. Proceedings of the international conference on research in engineering education; 2007.

[6] Tinto V. Leaving college: Rethinking the causes and cures of student attrition. University of Chicago Press, 5801 S. Ellis Avenue, Chicago, IL 60637; 1987.

[7] Anderson-Rowland MR. In: Understanding freshman engineering student retention through a survey. Proceedings, american society for engineering education annual conference; 1997. 